\title{
Designing sustainable supply chain network by considering direct and indirect shipment: Evidence from food industry
}

\author{
Zahra Mohammadi $^{a}$, Farnaz Barzinpour ${ }^{b^{*}}$ and Ebrahim Teimoury ${ }^{b}$
}

${ }^{a}$ PhD. candidate, School of Industrial Engineering, Iran University of Science and Technology, Iran ${ }^{b}$ Associate Professor, School of Industrial Engineering, Iran University of Science and Technology, Iran

\begin{tabular}{l}
\hline C H R O N I C L E \\
\hline Article history: \\
Received February 23, 2020 \\
Received in revised format: \\
May 9, 2020 \\
Accepted May 92020 \\
Available online \\
May 9, 2020 \\
\hline Keywords: \\
Supply Chain Design \\
Multi Objective \\
Perishability \\
Social Responsibility \\
Wastewater Treatment \\
Augmented E-constraint \\
\end{tabular}

\begin{abstract}
A B S T R A C T
Nowadays, special attention has been paid to the environmental and social issues in both developed and developing countries. Therefore, research on the sustainable supply chain is greatly expanded dramatically over the years. In some industries like food industry, these issues are more significantly emphasized because of the particular characteristics the food products. In this paper, we considered a multi-objective model for designing the sustainable supply chain in the processed food industry with fixed shelf-life products. Model objectives include economic with profit maximization as an economic index, environmental with the index of carbon dioxide emissions and wastewater treatment in manufacturing sector and social objectives with maximizing the amount of jobs created as a social index. For the proposed model, in addition to determining the optimal location of the facility and the flow rate between facility, the type of delivery of products is determined either directly from plant or indirectly from distribution centers with mechanized transportation system. Finally, the model is implemented in a processed food industry as a case study in Iran and is solved via the augmented $\varepsilon$-constraint method.
\end{abstract}

\section{Introduction}

The supply chain management is considered as a global strategy aimed to achieve organizational competitiveness. Designing the supply chain network involves strategic decisions that can determine the overall supply chain configuration. In these problems, mostly the optimal location of the various facilities is focused. Observing the sustainability in supply chains can decrease costs and environmental effects and increase social impacts. The supply chain for short-life and perishable goods has been one of the most important and challenging issues of management. On the other hand, people life style and manner have been affected by technology progress and development in all over the world. The results of these advances are visible in all aspects of life, including food preparation and consumption patterns. Therefore, an efficient supply chain management for food is ranked as the highest important issue. The food supply chain includes qualitative and quantitative factors. In recent years, the food industry in Iran has evolved into one of the most advanced industries and plays a special role in the country's development. This industry has a better competitive position than other industries in the country. The review of literatures shows that simultaneous consideration of profit functions, environmental and social impacts on the food supply chain for perishable products with fixed shelf life(expire date) was ignored in literature. In most articles that discuss environmental impacts, only carbon dioxide emissions have been observed and other factors such as the amount of wastewater treatment have been neglected.

* Corresponding author. Tel.: +98 2173225063

E-mail address: barzinpour@iust.ac.ir (F. Barzinpour) 
Other social factors such as job creation have also been disregarded. Another issue that has been neglected was the direct and indirect delivery of final products. Therefore this study is about designing the processed food supply chain with fixed shelf life. Also, because of product perishability, the inventory decay in distribution centers is observed. In order to make the responsible chain, the direct and indirect transmissions are surveyed. Finally, our model will be applied to a case study of processed food. In general, the main innovations that distinguish this research from the previous ones are:

- A novel mathematical model for designing a sustainable food processed supply chain network considering the wastewater filtration and job created,

- Considering the important decision such as direct and indirect shipment,

- Considering the important decisions such as defining the fix shelf life for perishability and penalty cost for decay of final products,

- Implementation of the proposed model for processed food chain.

The reminder of the paper is organized into 7 sections. After the introduction, Section 2, presents the literature review. In Section 3, presents the problem description. In Section 4, the mathematical formulation is described. The solution method is presented in Section 5.Section 6 reports the case study. The computational results and in the sensitivity analyses are presented in Section 7. Finally, Section 8 presents the conclusions and outlines future studies.

\section{Literature review}

Studies show designing food supply chain network has been ignored somehow in spite of the food importance. For example, for the first time Apaiaha et al. (2005) investigated simultaneously the quality and environmental objectives for food supply chain design. In a study of Shrimp Supply Chain in Thailand, Atthirawong and Choomrit (2006) investigated the targets of controlling final product quality, minimizing the costs and environmental effects. Yakovleva et al. (2010) presented a survey on the sustainability of the supply chain. Then, a new approach was presented considering all three sustainability factors in all stages of the supply chain from food to retailers and caterings. Rong et al.(2011) aimed at minimizing the total cost of the chain, the discussion of the degradation of food quality, which is dependent on temperature and transportation time, was integrated into the decisionmaking process of the single product multi-period, production and distribution chain. Among them, Grunow and Piramuthu (2013) reduced waste of food chain using Radio Frequency Identification

(RFID) technology. In fact, the terms will be made for members of perishable goods supply chain with concentrating on rest lifetime and the expiry date in order to maximize their profit. Yu and Nagurney (2013) offered a food supply chain model based on exclusive competition and focused on freshness of product with the goal of maximizing chain profit. In this model, food deterioration is compounded to including the disposing costs of corrosive food products through an increasing curve. Also, a multiobjective model was presented by Varsei and Polyakovskiy (2015) for the wine product with respect to all three sustainability criteria when the three dimensions were not visited together. In a research by Chaabane and Geramianfar (2015), a multi-objective decision framework was proposed to optimize multi-product multi-period sustainable supply chain. Jonkman et al. (2016) in a study conducted on the raw material of sugar beet considering the supply chain approach, showed that selecting food production process plans from agricultural products is important to reduce the costs. Mogale et al. (2016) studied the transportation and allocation of the Indian Public Distribution System (PDS) for edible seeds such as cereals grains supply chain with the goal of minimizing costs. Amorim et al. (2016) proposed a model for selecting suppliers in processed food supply chain in which the suppliers are chosen firstly, and then decay and product lifecycle and uncertainties in downstream and upstream are discussed. Mohammed and Wang (2017) proposed a multi-objective fuzzy scheduling model for planning the 3-level green distribution supply chain of meat in order to minimize costs and environmental impacts and maximize the average delivery rate. Rahimi and Ghezavati (2018), through two-step method, at first suppliers selection was considered using Analytical hierarchy process (AHP) 
and Ordered Weighted Averaging (OWA) methods. Then, in the second step, a multi-objective mathematical model was proposed for designing the supply chain network using the first stage results. In this model, the three dimensions of sustainability are defined. Accorsi (2018) presented the multi objective model for two alternative supply scenarios of tomatoes in the Mediterranean basin that was built upon three main linear functions for the overall food chain costs (i.e. fixed and variables), the GHGs emissions (i.e. caused land-use location and supply chain operations), and energy requirements (i.e. to fuel crops, facilities, and supply chain operations) respectively. Rohmer et al. (2018) presented a novel application of a network design problem, addressing sustainability issues in the context of the global food system. Taking into account several echelons and interlinkages between different food supply chains, the paper broadened the scope of the considered network and incorporates sourcing, processing and transportation decisions within a common framework. While minimizing different environmental and economic objectives, the model aims to maintain a sufficient dietary intake level. Consumption decisions were incorporated in the model through different types of consumer demands.

In a another study, Onggo et al. (2019) considered an agri-food supply chain with a single fresh food supplier, who owns a central warehouse that served several retail centers. Retail centers carried a certain amount of inventory of the fresh product, which was prone to deterioration. The supplier made both inventory and routing decisions to minimize the inventory, transportation, food-waste, and stock-out costs in the face of stochastic customer demand and perishable products that needed to be delivered to each retail center. Mohebalizadehgashti et al.(2020) developed a multi-objective mixed-integer linear programming formulation considering environmental concerns in a mathematical model to design and configure a multi-period, multi-product, multi-echelon green meat supply chain network. Seyyed Jifroudi et al. (2020) considered proposed a mixed-integer linear mathematical model for designing and planning of rice supply chain which aims to maximize total profit by integrating different decisions of the rice supply chain.

Type and amount of demand are considered as a main factor in inventory control. Considering perishability of products in processed food chain as specific kind of products, the type of perishability can be important; which means that if the products life time is fixed or variable, in the case of variability, rates of perishability is important in inventory control. In most inventory models, the goal is to minimize the costs such as ordering, transmission, holding, decay expenditures, etc. In most of the models for perishable products in the literature, perishable rates are considered as fixed, just in a few studies have been conducted on perishable products with fixed shelf life. For example, Kouki et al. (2009) studied a model for a perishable inventory control under review policy (r, Q) for items with fixed shelf life aimed to minimize the costs. In another study, Nakhai Kamalabadi et al. (2009) proposed three models of three-level inventory control for perishable items with an expire date considering Just In Time (JIT) policy to optimize the total cost of the supply chain. Among them, Hiassat and Diabat (2011) and Hiassat et al. (2017) presented a location-inventory-routing model aimed to minimize the costs for perishable items with fixed shelf-life. Amorim et al. (2012 examined a multi-objective framework to survey the benefits of integrating the production and distribution of perishable products in strategic level with the goals of minimizing costs and maximizing the average products shelf-life stability in distribution centers at the planning horizon. Zhang et al. (2014) investigated the coordination between an integrated system of production-inventory by considering the discount for products with a fixed life time and the rate of limited production and definite demand in both centralized and noncentralized situations. In both cases, the goal was to minimize the cost of the chains by utilizing discounted contracts in order to improve the efficiency of the chain. In a research by Kalantari and Pishvaee(2016), a main planning model was presented for a multi-level supply chain in which product life time is fixed as well as, delivering a product on time is an effective way to make the chain responsive and customers satisfied. In the food supply chain, products quality and freshness are greatly important, so considering directly and indirectly shipment may have an impact on our goal to deliver fresh and high quality products. Although direct shipment associated to higher costs, the amount of inventory and holding costs decreased. In most reviewed articles, distribution of products is considered through distribution centers or wholesales. In a few articles, direct shipment from plants to retailers has 
been addressed. For example, Klincewicz (1990), defined a three-level supply chain to minimize costs, in which final products can either be delivered directly from suppliers or through a series of terminals toward distribution centers to satisfy demand. Min et al.(2006a) studied the direct and indirect delivery of products from the final customer to the aggregation centers in a backward supply chain to minimize costs. Min et al.(2006b) investigated a direct shipment from a customer to aggregate centers in a closed loop supply chain. Min and Ko (2008) addressed the issue of direct shipment by customers to the factory despite high cost of direct shipping in contrast to dispatching via aggregation centers or repair centers. Furthermore, Pishvaie and Rabbani (2011) designed a multi-level responsive supply chain under two conditions, where direct transmission is feasible and direct transportation is not possible, with the aim of minimize costs. Rianthong and Dumrongsiri(2013) used an integrated decision making solution for production, inventory and transportation to minimize direct transportation costs. There are no distribution centers in this model. Goodarzi and Zegordi (2016) developed a mixed-integer nonlinear programming formulation for the problem in which the location for establishing the cross-docks was determined while simultaneously a fleet of vehicles were applied to transport goods from suppliers to the assembly plants via two transportation strategies: direct shipment and shipment through cross-dock (indirect shipment). Barzinpour and Taki (2018) presented a dual-channel network design model in a green supply chain that classified markets into two groups. First one compared was associated with those customers order directly to plants as direct channel (on-line ordering). The second group was related to those customers who order indirectly to the supply chain. Therefore, their demand were satisfied by distribution centers through the indirect channel.

\section{Problem description}

The supply chain was a delivery cycle of the final products to the consumer. The studied supply chain network in the prevent study included a number of suppliers, plants, distribution centers and retailers. The location of suppliers and retailers was already known. The demand of retailers was also known and fixed. The locations of production and distribution centers were chosen from potential points of establishment. The chain was defined for some perishable final product with fixed shelf life. Mechanized transport equipment with different capacities was used for handling final products depending on their type of perishability. Different row materials were supplied from various suppliers. There were two ways for dispatching the final products to retailers, the first one was direct delivery from the plant to retailers and the other one was the indirect delivery through distribution centers. The proposed models aimed to locate plants and distribution centers with regards to increase profit by decreasing the costs for establishing plants and distribution centers, purchasing raw materials and holding cost of final products in distribution centers, total cost of transportation in the whole chain, the cost of wastewater treatment and degradation the final product in distribution centers; minimizing environmental impacts such as $\mathrm{Co}_{2}$ emissions which is coming from establishing plants and distribution centers and transportation between the various parts of the chain; and maximizing the index of employment are made by opening of plants and distribution centers as a social indicator. Fig. 1 shows the considered supply chain network structure. The main assumptions of the problem were:

1. There are two fixed and variable costs for the opening the plants and distribution centers; the fixed cost is the same for everyone and the variable is a coefficient of fixed cost;

2. The system includes several products;

3. The final products are perishable and have expire dates (fixed shelf life);

4. The expiration period of the final products is the correct multiplication of the length of periods;

5. The final products sent from the production center are in the beginning of the expiration period (new product);

6. Storage system for final products in distribution centers is FIFO; 


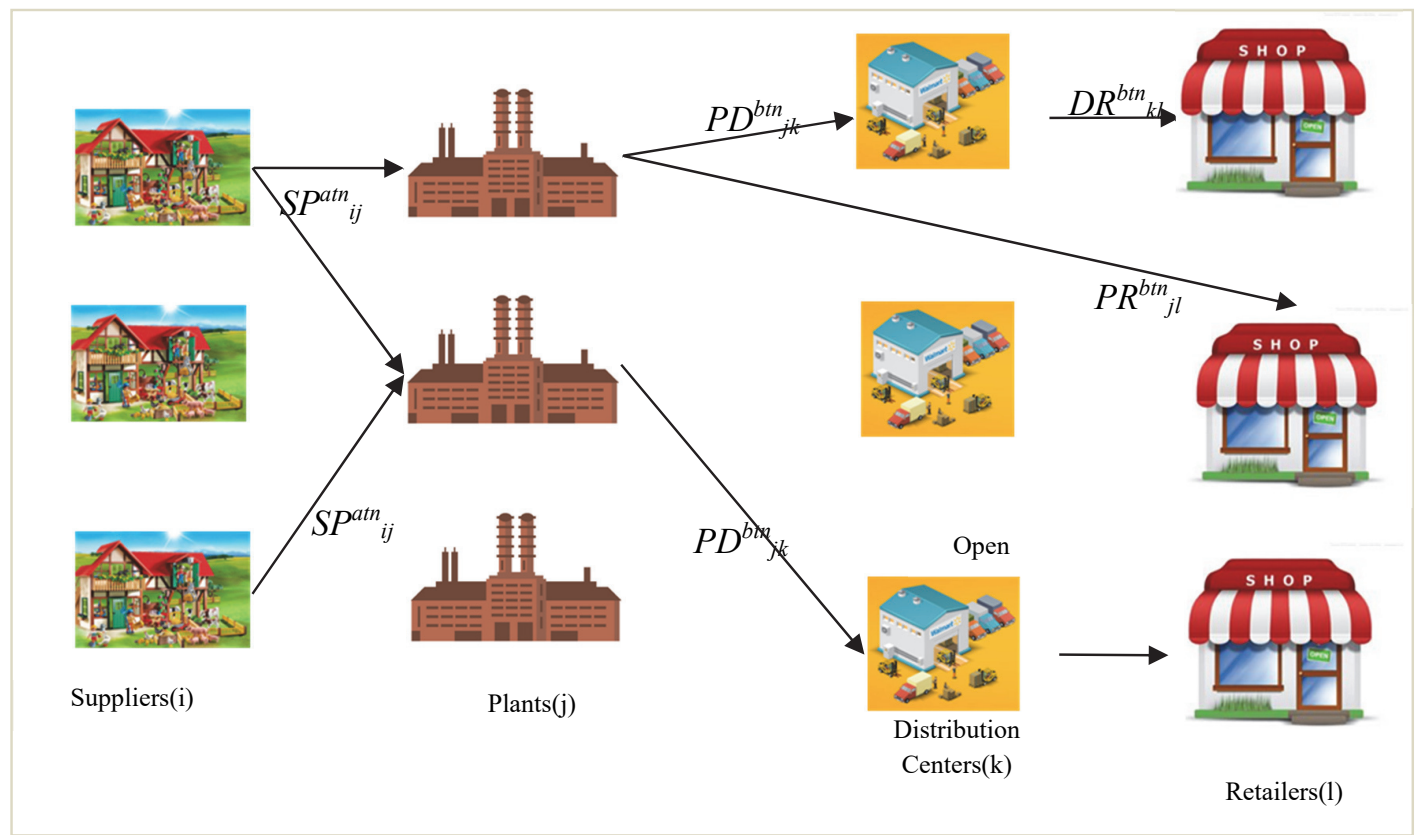

Fig. 1. The structure of the proposed supply chain network in the present study

7. Suppliers, plants and distribution centers have a capacity constraint;

8. The amount of the demand from retailers is known and fixed in each period;

9. Demand of retailers should be satisfied in each period;

10. The transportation equipments are mechanized and have different capacities;

11. Retailers can satisfy their own demand by direct shipment from the plant or by indirect shipment through distribution centers;

12. The amount of $\mathrm{Co}_{2}$ released by the carriers depends on the distance between the two points and the number of carriers transported between them.

\section{Mathematical model}

In this section the mathematical model of the described problem for the previous section is presented.

\subsection{Notations}

The indexes, parameters, and decision variables are defined as follows:

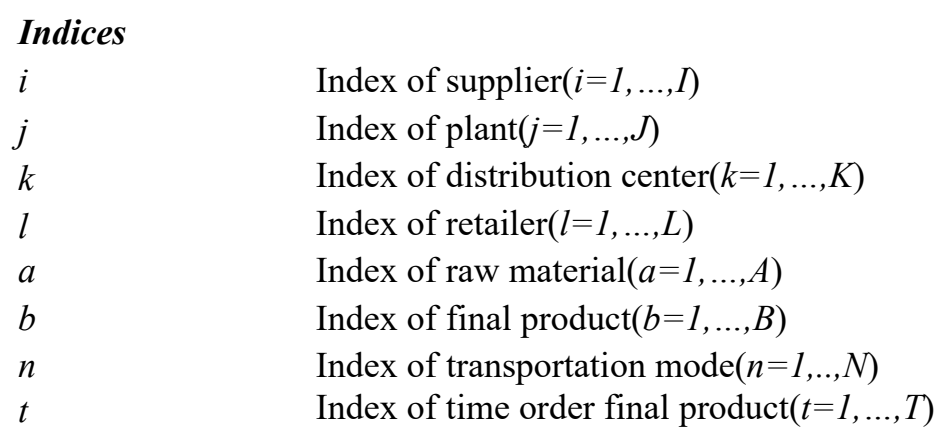

\section{Parameters}

$D^{b t}{ }_{l}$

$\operatorname{Pr}^{b}{ }_{j l}$

$\operatorname{Pr}^{b}{ }_{k l}$

$F P_{j}$
Demand of retailer $l$ in period $t$ for final product $b$.

Sale price of each unit of final product $b$ that sent from plant $j$ to retailer $l$ in period $t$. Sale price of each unit of final product $b$ that sent from distribution center $k$ to retailer $l$ in period $t$.

Fixed cost of opening a plant in the candidate location $j$ 
Coefficient variable cost for opening a plant in the candidate location $j$

Fixed cost of opening a distribution center in the candidate location $k$

Coefficient variable cost for opening a distribution center in the candidate location $k$

Ordering cost placed to the supplier $i$ for row material $a$

Capacity of supplier $i$ for row material $a$

Capacity of plant $j$ for final product $b$

Capacity of distribution center $k$ for final product $b$

Capacity of transportation mode $n$

Capacity of wastewater facility in plant $j$

Cost of final product decay in distribution center

Expire date for final product $b$

Transportation cost for raw material $a$ by mode $n$ between supplier $i$ and plant $j$

Transportation cost by mode $n$ between plant $j$ and distribution center $k$

Transportation cost by mode $n$ between plant $j$ and retailer $l$

Holding cost for final product $b$ in distribution center $k$

Cost of purchasing each unit of fresh water in plant $j$

Filtration cost for each unit of wastewater in plant $j$

Penalty cost for each unit of non-filtration wastewater

Maximum acceptable level for dumping non-filtration wastewater

Wastewater filtration rate in plant $j$

Amount of water needed to prepare each unit of the row material $a$ in plant $j$

Processing cost for each unit of row material $a$ in plant $j$

Distance between supplier $i$ for row material $a$ to plant $j$

Distance between plant $j$ to distribution center $k$

Distance between plant $j$ to retailer $l$

Distance between distribution center $k$ to retailer $l$

Number of created job opportunities if plant $j$ is opened

Number of created job opportunities if distribution center $k$ is opened

Unemployment rate at plant node $j$

Unemployment rate at distribution center $k$

$\mathrm{CO}_{2}$ emission in gram for opening plant $j$

$\mathrm{CO}_{2}$ emission in gram for opening distribution center $k$

$\mathrm{CO}_{2}$ emission in gram per kilometer for transportation mode $n$

Big number

Variables

$\begin{array}{ll}S P^{a t n}{ }_{i j} & \begin{array}{l}\text { Quantity of raw material } a \text { shipped from supplier } i \text { to plant } j \text { during period } t \text { by transportation } \\ \text { mode } n\end{array} \\ P D^{b t n}{ }_{j k} & \begin{array}{l}\text { Quantity of final product } b \text { shipped from plant } j \text { to distribution center } k \text { during period } t \text { by } \\ \text { transportation mode } n\end{array} \\ P R^{b t n}{ }_{j l} & \begin{array}{l}\text { Quantity of final product } b \text { shipped from plant } j \text { to retailer } l \text { during period } t \text { by transportation } \\ \text { mode } n\end{array} \\ D R^{b t n}{ }_{k l} & \begin{array}{l}\text { Quantity of final product } b \text { shipped from distribution center } k \text { to retailer } l \text { during period } t \text { by } \\ \text { transportation mode } n\end{array} \\ I n^{b t}{ }_{k} & \text { Inventory level of final product } b \text { in distribution center } k \text { at the end of period } t \\ P_{j} & \text { Binary variable equal to } 1 \text { if plant } j \text { is established, otherwise to } 0\end{array}$

\subsection{Model}

The mixed-integer linear programming model for four-level processed food supply chain network design is as follows: 
$\max$ profit $=\left[\sum_{b} \sum_{t} \sum_{j} \sum_{l} \sum_{n} P r_{j l}^{b} \cdot P R_{j l}^{b t n}+\sum_{b} \sum_{t} \sum_{k} \sum_{l} \sum_{n} P r_{k l}^{b} . D R_{k l}^{b t n}\right]$

$-\left[\sum_{j} P_{j} \cdot F P_{j}(1+\alpha)+\sum_{k} D C_{k} \cdot F D_{k}(1+\beta)+\sum_{a} \sum_{i} \sum_{j} \sum_{t} \sum_{n} C_{i}^{a} \cdot S P_{i j}^{a t n}\right.$

$+\sum_{a} \sum_{i} \sum_{j} \sum_{t} \sum_{n}\left\lceil\frac{S P_{i j}^{a t n}}{C T_{n}}\right\rceil \cdot T C_{i j}^{a n}+\sum_{b} \sum_{t} \sum_{j} \sum_{k} \sum_{n} \sum_{n}\left\lceil\frac{P D_{j k}^{b t n}}{C T}\right\rceil . T C_{j k}^{n}$

$+\sum_{b} \sum_{t} \sum_{j} \sum_{l} \sum_{n}\left\lceil\frac{P R_{j l}^{b t n}}{C T}\right\rceil . T C_{j l}^{n}+\sum_{b} \sum_{t} \sum_{k} \sum_{l} \sum_{n}\left\lceil\frac{D R_{k l}^{b t n}}{C T}\right\rceil . T C_{k l}^{n}$

$+\sum \sum \sum H_{k}^{b} \cdot \operatorname{In}_{k}^{b t}$

$+\sum_{a}^{b} \sum_{i}^{t} \sum_{j}^{k} \sum_{t} \sum_{n}\left(\rho_{j} \cdot Q_{j}^{a} \cdot E W_{j}+\left(1-\rho_{j}\right) Q_{j}^{a} \cdot \eta_{j}+Q_{j}^{a} \cdot E F_{j}\right) S P_{i j}^{a t n}$

$\left.+\left(\sum_{t} \sum_{b} \sum_{j} \sum_{k} \sum_{n} P D_{j k}^{b t n}-\sum_{b} \sum_{t^{\prime}} \sum_{l} D_{l}^{b t^{\prime}}\right) \cdot w\right]$

$\max j o b$ created $=\sum_{j} J C U P_{j} \cdot u p_{j} \cdot P_{j}+\sum_{k} J C U D_{k} \cdot u p_{k} \cdot D C_{k}$

min environmental effect $=\sum_{j} C o_{2} . P_{j}$

$$
\begin{aligned}
& +\sum_{k} \mathrm{Co}_{2_{k}} . D C_{k} \\
& +\sum_{a} \sum_{i} \sum_{j} \sum_{t} \sum_{n} C o_{2}\left\lceil\frac{S P_{i j}^{a t n}}{C T}\right\rceil d_{i j}^{a}+\sum_{b} \sum_{t} \sum_{j} \sum_{k} \sum_{n} C o_{2}\left\lceil\frac{P D_{j k}^{b t n}}{C T}\right\rceil d_{j k} \\
& +\sum_{b} \sum_{t} \sum_{j} \sum_{l} \sum_{n} C o_{2}\left\lceil\frac{P R_{j l}^{b t n}}{C T}\right\rceil d_{j l}+\sum_{b} \sum_{t} \sum_{k} \sum_{l} \sum_{n} C o_{2}\left\lceil\frac{D R_{k l}^{b t n}}{C T}\right\rceil d_{k l}
\end{aligned}
$$

Subject to:

$S P_{i j}^{a t n} \leq M \cdot P_{j}$

$\forall a, t, i, j, n$

$P D_{j k}^{b t n} \leq M \cdot P_{j}$

$\forall b, t, j, k, n$

$P D_{j k}^{b t n} \leq M \cdot D C_{k}$

$\forall b, t, j, k, n$

$P R_{j l}^{b t n} \leq M \cdot P_{j}$

$\forall b, t, j, l, n$

$D R_{k l}^{b t n} \leq M . D C_{k}$

$\forall b, t, k, l, n$

$\sum \sum_{n} S P_{i j}^{a t n} \leq C S_{i}^{a}$

$\forall a, i, t$

$\sum_{l}^{j} \sum_{n}^{n} P R_{j l}^{b t n}+\sum_{k} \sum_{n} P D_{j k}^{b t n} \leq C P_{j}^{b} \cdot P_{j}$

$\forall b, t, j$

$I n_{k}^{b t} \leq C D_{k}^{b} \cdot D C_{k}$

$I n_{k}^{b t}=I n_{k}^{b(t-1)}+\sum_{j} \sum_{n} P D_{j k}^{b t n}-\sum_{l} \sum_{n} D R_{k l}^{b t n}$

$\forall b, t, k$

$S P_{i j}^{a t n} \leq C t_{n} \cdot T r_{n}^{t}$

$\forall b, t, k$

$\sum P D_{j k}^{b t n} \leq C t_{n} \cdot T r_{n}^{t}$

$\sum^{b}$

$\sum P R_{j l}^{b t n} \leq C t_{n} \cdot \operatorname{Tr}_{n}^{t}$

$\forall a, i, j, t, n$

$\sum^{b}$

$\sum D R_{k l}^{b t n} \leq C t_{n} \cdot T r_{n}^{t}$

$\forall t, j, k, n$

$\sum_{a}^{b} \sum_{i} \sum_{t} \sum_{n} \rho_{j} \cdot Q_{j}^{a} \cdot S P_{i j}^{a t n} \leq P_{j} \cdot C W_{j}$

$\forall t, j, l, n$

$\forall t, k, l, n$

$\forall j$ 


$$
\begin{array}{ll}
\sum_{a} \sum_{i} \sum_{t} \sum_{n}\left(1-\rho_{j}\right) Q_{j}^{a} . S P_{i j}^{a t n} \leq \Omega & \forall j \\
\sum_{i} \sum_{n} S P_{i j}^{a t n} \geq r_{b}^{a}\left(\sum_{l} \sum_{n} P R_{j l}^{b t n}+\sum_{k} \sum_{n} P D_{j k}^{b t n}\right) & \forall a, b, t, j \\
\sum_{j}^{j} P D_{j k}^{b t}+I n_{k}^{b(t-1)} \geq \sum_{l}^{D} D R_{k l}^{b t} & \forall b, t, k \\
\sum_{j} \sum_{n} P R_{j l}^{b t n}+\sum_{k} \sum_{n} D R_{k l}^{b t n}=D_{l}^{b t} & \forall b, t, l \\
\sum_{t^{\prime}=1}^{t} \sum_{j} \sum_{n} P D_{j k}^{b t t^{\prime} n}>\sum_{t^{\prime}=1} \sum_{l} D_{l}^{b t^{\prime \prime}} & \\
S P_{i j}^{a t n}, P R_{j l}^{b t n}, P D_{j k}^{b t n}, D R_{k l}^{b t n}, I n_{k}^{b t} \geq 0 & \\
P_{j}, D C_{k}, T r_{n}^{t} \in(0,1) &
\end{array}
$$

The model had three objective functions. The first one (1) maximizes the profit. In this function, in the first part, the revenue from the supply chain is considered with direct and indirect shipment. The expenditures include the costs for establishing the plants and distribution centers, purchasing raw materials from suppliers, transportation among all parts of the chain, holding the final product at distribution centers, wastewater treatment and final products decay at distribution centers. The second objective (2) maximizes job opportunity in the places where plant and distribution centers are established. The third objectives (3) is associated with minimization of the amount of $\mathrm{CO}_{2}$ emissions as a result of launching plants and distribution centers and transportation system throughout the chain.

Constraints (4), (5), (6), (7) and (8), respectively determine the amount of raw material sent from suppliers to plants, final products from plants to distribution centers or retailers and from distribution centers to retailers. Constraints (9), (10) and (11) guarantee the limited capacity of suppliers, plants and distribution centers. Constraint (12), determined the amount of inventory in distribution center. Constraints (13), (14), (15) and (16) relate to the capacity of the transportation vehicle. Constraint (17) relates to the capacity limitations of wastewater treatment facilities. Constraint (18) ensures that the amount of wastewater entering the environment do not exceed the permissible limit. Constraints (19) and (20) are equilibrium constraints. Constraint (21) ensures that the demand of retailer should be satisfied. Constraint (22) related to decay the final product in the distribution centers. Constraints (23) and (24) show the type of problem decision variables.

\section{Solution Method}

Considering the dimensions of the case study, the exact method of augmented $\varepsilon$-constraint is used to solve the proposed model in the case study. AUGMECON enhances the conventional $\varepsilon$-constraint method for generating the pareto optimal solutions in multi-Objective mathematical programming problems. AUGMECON addresses some weak points of the conventional $\varepsilon$-constraint, namely, the guarantee of Pareto optimality of the obtained solution in the payoff table as well as in the generation process and the increased solution time for problems with several (more than two) objective functions. In the original AUGMECON method the problem solved is the following (Mavrotas \& Florios(2013)):

$\max \left(f_{1}(x)+e p s \times\left(S_{2} / r_{2}+S_{3} / r_{3}+\cdots+S_{p} / r_{p}\right)\right)$

st

$f_{2}(x)-S_{2}=e_{2}$

$f_{3}(x)-S_{3}=e_{3}$

$f_{p}(x)-S_{p}=e_{p}$

$x \in S$ and $S_{i} \in R^{+}$ 
where $e_{2}, e_{3}, \ldots, e_{p}$ are the parameters for the RHS for the specific iteration drawn from the grid points of the objective functions $2,3, \ldots, p$. The parameters $r_{2}, r_{3}, \ldots, r_{p}$ are the ranges of the respective objective functions. $S_{2}, S_{3}, \ldots, S_{p}$ are the surplus variables of the respective constraints and eps $\epsilon\left[10^{-6}, 10^{-3}\right]$. In AUGMECON2, the improved version of AUGMECON we slightly modify the objective function as follows:

$\max \left(f_{1}(x)+\right.$ eps $\left.\times\left(S_{2} / r_{2}+10^{-1}+S_{3} / r_{3}+10^{-2}+\cdots+10^{-(p-2)}+S_{p} / r_{p}\right)\right)$

This modification is done in order to perform a kind of lexigographic optimization on the rest of the objective functions if there are any alternative optima. For example, with this formulation the solver will find the optimal for $f_{1}$ and then it will try to optimize $f_{2}$, then $f_{3}$ and so on. With the previous formulation the sequence of optimizations of $f_{2}-f_{p}$ was indifferent, while now we force the sequential optimization of the constrained objective functions (in case of alternative optima). As it is explained in (Mavrotas and Florios, 2013), for each objective function 2, .., $p$ we calculate the objective function range. Then we divide the range of the $k$-th objective function to $q_{k}$ equal intervals using $\left(q_{k}-1\right)$ intermediate equidistant grid points. Thus we have in total $\left(q_{k}+1\right)$ grid points that are used to vary parametrically the RHS $\left(e_{k}\right)$ of the k-th objective function. The total number of runs becomes $\left(q_{2}+1\right)^{*}\left(q_{3}+1\right)^{*} \ldots *\left(q_{p}+1\right)$. Let $r k$ be the range of the objective function $k(k=2, \ldots, p)$. Then the discretization step for this objective function is given as:

$\operatorname{step}_{k}=r_{k} / q_{k}$.

The RHS of the corresponding constraint in the $t$-th iteration in the specific objective function will be:

$e_{k t}=\operatorname{fmin}_{k}+t \times$ step $_{k}$,

where $\min _{\mathrm{k}}$ is the minimum from the payoff table and $t$ the counter for the specific objective function. In each iteration we check the surplus variable that corresponds to the innermost objective function. In this case it is the objective function with $p=2$. Then we calculate the bypass coefficient as:

$b=\operatorname{int}\left(S_{2} /\right.$ step $\left._{2}\right)$

where $\operatorname{int}\left(\right.$ ) is the function that returns the integer part of a real number. When the surplus variable $S_{2}$ is larger than the step2, it is implied that in the next iteration the same solution will be obtained with the only difference being the surplus variable which will have the value $S_{2}$-step2. This makes the iteration redundant and therefore we can bypass it as no new Pareto optimal solution is generated. The bypass coefficient $\mathrm{b}$ actually indicates how many consecutive iterations we can bypass Mavrotas and Florios (2013). Using augmented $\varepsilon$-constraint objective function and considering the model constraints, we have a single objective, mixed integer programming model, which can be efficiently solved by linear programming solvers.

\section{Case study}

In this section, the proposed model was implemented in a case study in processed food industry in Iran. The supply chain was related to processed food product, two types of kielbasa $(97 \%$ meat kielbasa and $97 \%$ chicken kielbasa) and sausage (30\% meat and 60\% chicken sausage). In the chain studied, there were two types of raw materials, chicken and meat; each of the raw materials can be purchased from several suppliers. The potential locations for the establishment of production centers were considered in the suburbs of Tehran. Finished products were distributed in Tehran, Alborz, Qazvin and Qom provinces. If the retailers were within the radius of coverage the production center, it was possible to send them the final products directly from the factory. Otherwise distribution centers would be established and the final products would be distributed indirectly through distribution centers. Final products were perishable and had a fixed shelf life (expiration date). The maximum usable time for final products was 42 days( 6 weeks) after production. Distribution center ordered the final products from plants every two week. Depending on the type of final products, they were transported via a mechanized mode with variable capacity. The demand of distribution centers were already known. Distribution centers laid their orders for the final products every other week. Distribution centers stored 
final products until they reached the expiration date. Decay and the decay cost would be defined if the final products were not sold during the shelf life time. The cost of decay was also considered to be the same in the distribution centers. This problem has been solved with dimensions: $i=3, j=2, k=4,1=$ $12, a=2, b=3, n=3$ and $t=8$. Data on this issue are shown in Tables 1 to Table 15 .

\section{Table 1}

Retailers' demand for different products at different periods $\left(\mathrm{D}^{\mathrm{bt}}{ }_{1}\right)(\mathrm{kg})$

\begin{tabular}{|c|c|c|c|}
\hline b & 1 & 2 & 3 \\
\hline & \multicolumn{3}{|c|}{$\mathrm{t}$} \\
\hline 1 & $1-8$ & $1-8$ & $1-8$ \\
\hline 1 & 250 & 260 & 300 \\
\hline 2 & 270 & 240 & 280 \\
\hline 3 & 300 & 310 & 350 \\
\hline 4 & 350 & 320 & 350 \\
\hline 5 & 280 & 300 & 340 \\
\hline 6 & 200 & 240 & 290 \\
\hline 7 & 230 & 330 & 350 \\
\hline 8 & 240 & 350 & 340 \\
\hline 9 & 300 & 240 & 320 \\
\hline 10 & 310 & 230 & 330 \\
\hline 11 & 240 & 290 & 300 \\
\hline 12 & 350 & 300 & 340 \\
\hline
\end{tabular}

Table 2

Sales price of final products from distribution centers to retailers $\left(\operatorname{Pr}_{\mathrm{kl}} \mathrm{k}\right)\left(\mathrm{Rial} \times 10^{4}\right)$

\begin{tabular}{|c|c|c|c|c|c|c|c|c|c|c|c|c|}
\hline \multirow{3}{*}{$\begin{array}{l}\mathrm{b} \\
1\end{array}$} & \multicolumn{4}{|c|}{1} & \multicolumn{4}{|c|}{2} & \multicolumn{4}{|c|}{3} \\
\hline & \multicolumn{12}{|c|}{$\mathrm{k}$} \\
\hline & 1 & 2 & 3 & 4 & 1 & 2 & 3 & 4 & 1 & 2 & 3 & 4 \\
\hline 1 & 130 & - & - & - & 75 & - & - & - & 70 & - & - & - \\
\hline 2 & 130 & - & - & - & 75 & - & - & - & 70 & - & - & - \\
\hline 3 & 130 & - & - & - & 75 & - & - & - & 70 & - & - & - \\
\hline 4 & 130 & - & - & - & 75 & - & - & - & 70 & - & - & - \\
\hline 5 & - & 130 & - & - & - & 75 & - & - & - & 70 & - & - \\
\hline 6 & - & 130 & - & - & - & 75 & - & - & - & 70 & - & - \\
\hline 7 & - & 130 & - & - & - & 75 & - & - & - & 70 & - & - \\
\hline 8 & - & - & 130 & - & - & - & 75 & - & - & - & 70 & - \\
\hline 9 & - & - & 130 & - & - & - & 75 & - & - & - & 70 & - \\
\hline 10 & - & - & 130 & - & - & - & 75 & - & - & - & 70 & - \\
\hline 11 & - & - & - & 130 & - & - & - & 75 & - & - & - & 70 \\
\hline 12 & - & - & - & 130 & - & - & - & 75 & - & - & - & 70 \\
\hline
\end{tabular}

Table 3

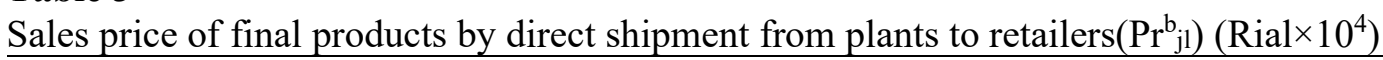

\begin{tabular}{|c|c|c|c|c|c|c|}
\hline \multirow[t]{2}{*}{$\mathrm{b}$} & \multicolumn{2}{|c|}{1} & \multicolumn{2}{|c|}{2} & \multicolumn{2}{|c|}{3} \\
\hline & & & & & & \\
\hline 1 & 1 & 2 & 1 & 2 & 1 & 2 \\
\hline 1 & 120 & 120 & 65 & 65 & 60 & 60 \\
\hline 2 & 120 & 120 & 65 & 65 & 60 & 60 \\
\hline 3 & 120 & 120 & 65 & 65 & 60 & 60 \\
\hline 4 & 120 & 120 & 65 & 65 & 60 & 60 \\
\hline $5-12$ & - & - & - & - & - & - \\
\hline
\end{tabular}

Table 4

$\underline{\text { Maximum Capacity of Plants }\left(\mathrm{CP}_{\mathrm{j}}^{\mathrm{b}}\right)\left(\mathrm{kg} \times 10^{3}\right)}$

\begin{tabular}{cccc}
\hline & & $\mathrm{b}$ & \\
\cline { 2 - 4 } $\mathrm{j}$ & 1 & 2 & 3 \\
\hline 1 & 2.5 & 3 & 2.5 \\
2 & 2.5 & 2.5 & 3 \\
\hline
\end{tabular}


Table 5

Maximum Capacity of Supplier $\left(\mathrm{CS}^{\mathrm{a}} \mathrm{i}\right)\left(\mathrm{kg} \times 10^{3}\right)$

\begin{tabular}{lcc} 
& & $\mathrm{a}$ \\
$\mathrm{nyy}$ & 1 & 2 \\
\hline 1 & 3.5 & 3.5 \\
2 & 3.5 & 3.5 \\
3 & 3.5 & 3.5 \\
\hline
\end{tabular}

Table 6

Maximum Capacity of Distribution Centers $\left(\mathrm{CD}^{\mathrm{b}} \mathrm{k}\right)\left(\mathrm{kg} \times 10^{3}\right)$

\begin{tabular}{ccccc} 
& & $\mathrm{k}$ & 3 & 4 \\
\cline { 2 - 5 } & 1 & 2 & 1 & 1 \\
2 & 1.5 & 1 & 1 & 1 \\
3 & 1.5 & 1.5 & 1.5 & 1 \\
\hline
\end{tabular}

Table 7

Capacity of Transportation Mode $\left(\mathrm{CT}_{\mathrm{n}}\right)\left(\mathrm{kg} \times 10^{3}\right)$

$\begin{array}{lll}\mathrm{n} & 1 & 2 \\ \mathrm{CT} & 2 & 4\end{array}$

\section{Table 8}

Purchasing cost of the row material from suppliers $\left(\mathrm{C}^{\mathrm{a}} \mathrm{i}\right)\left(\mathrm{Rial} \times 10^{3}\right)$

\begin{tabular}{ccc}
$\mathrm{i}$ & 1 & 2 \\
\hline 1 & 65 & 250 \\
2 & 62 & 220 \\
3 & 63.5 & 240
\end{tabular}

\section{Table 9}

Distance between suppliers and plants $\left(\mathrm{d}^{\mathrm{a}}{ }_{\mathrm{ij}}\right)(\mathrm{km})$

\begin{tabular}{ccccccc}
\hline $\mathrm{a}$ & \multicolumn{1}{c}{} & \multicolumn{2}{c}{2} \\
\hline $\mathrm{j}$ & 1 & 2 & $\mathrm{i}$ & 1 & 2 & 3 \\
\hline 1 & 130 & 150 & 170 & 1000 & 800 & 950 \\
2 & 120 & 170 & 180 & 950 & 1000 & 1100 \\
\hline
\end{tabular}

\section{Table 10}

Distance between plants and distribution centers $\left(\mathrm{d}_{\mathrm{jk}}\right)(\mathrm{km})$

\begin{tabular}{ccccc}
\hline & \multicolumn{3}{l}{} \\
\hline $\mathrm{j}$ & 1 & 2 & 3 & 4 \\
1 & 110 & 170 & 200 & 190 \\
2 & 120 & 180 & 210 & 200 \\
\hline
\end{tabular}

\section{Table 11}

Distance between plants and retailers $\left(\mathrm{d}_{\mathrm{jl}}\right)(\mathrm{km})$

\begin{tabular}{cccccc}
\hline $\mathrm{j}$ & \multicolumn{5}{c}{1} \\
\cline { 2 - 6 } \\
\cline { 2 - 6 } & 1 & 2 & 3 & 4 & $5-12$ \\
2 & 190 & 210 & 250 & 220 & - \\
\hline
\end{tabular}

\section{Table 12}

Distance between distribution centers and retailers $\left(\mathrm{d}_{\mathrm{kl}}\right)(\mathrm{km})$

\begin{tabular}{|c|c|c|c|c|c|c|c|c|c|c|c|c|}
\hline \multirow[b]{2}{*}{$\mathrm{k}$} & \multicolumn{12}{|c|}{1} \\
\hline & 1 & 2 & 3 & 4 & 5 & 6 & 7 & 8 & 9 & 10 & 11 & 12 \\
\hline 1 & 30 & 25 & 20 & 15 & - & - & - & - & - & - & - & - \\
\hline 2 & - & - & - & - & 20 & 15 & 18 & - & - & - & - & - \\
\hline 3 & - & - & - & - & - & - & - & 20 & 30 & 15 & - & - \\
\hline 4 & - & - & - & - & - & - & - & - & - & - & 20 & 20 \\
\hline
\end{tabular}




\section{Table 13}

Holding cost for final products in distribution centers $\left(\mathrm{h}^{\mathrm{b}} \mathrm{k}\right)\left(\right.$ Rial $\left.\times 10^{6}\right)$

\begin{tabular}{cccc}
\hline & & $\mathrm{b}$ & \\
\cline { 3 - 4 } & 1 & 2 & 3 \\
\hline 1 & 5 & 5 & 5 \\
3 & 5 & 5 & 5 \\
4 & 5 & 5 & 5 \\
\hline
\end{tabular}

\section{Table 14}

Opening cost for plants and distribution centers $\left(\mathrm{FP}_{\mathrm{j}}\right.$ and $\left.\mathrm{FD} \mathrm{k}\right)\left(\mathrm{Rial}^{*} 10^{9}\right)$

\begin{tabular}{cccccccc}
\hline $\mathrm{j}$ & 1 & 2 & $\mathrm{k}$ & 1 & 2 & 3 & 4 \\
\hline $\mathrm{FP}$ & 60 & 65 & $\mathrm{FD}$ & 10 & 80 & 120 & 9 \\
\hline
\end{tabular}

Table 15

Number of job created and Unemployment rate in plants and distribution centers $\left(\mathrm{JCPP}_{\mathrm{j}}\right.$ and $\left.\mathrm{JCPD}_{\mathrm{k}}\right)$ (person)

\begin{tabular}{ccccccccc} 
& 1 & 2 & $\mathrm{k}$ & 1 & 2 & 3 & 4 \\
\hline JCPP & 25 & 27 & & JCPD & 6 & 7 & 6 & 7 \\
upp & 13.3 & 13.3 & & upd & 13.3 & 13.8 & 11 & 12.1 \\
\hline
\end{tabular}

\section{Computational results}

In this section, the proposed mathematical model was executed by the software GAMS 23.6 CPLEX Solver on a computer with Intel Core 2 and 4 GB. In this section, in order to validate the proposed model, sensitivity analyses were performed on some of the important parameters. The most important parameter of the proposed model is the amount of retailers demand in network which significantly influence impact the results. To show the effect of changing these parameters on the objective function, the value of this parameter is assumed to increase by 10, 20, 30, 40 and 50 percent. In Fig. 2, Fig. 3 and Fig. 4, respectively, the effect of these changes on the total profit, job opportunities and environmental indicators have been shown.

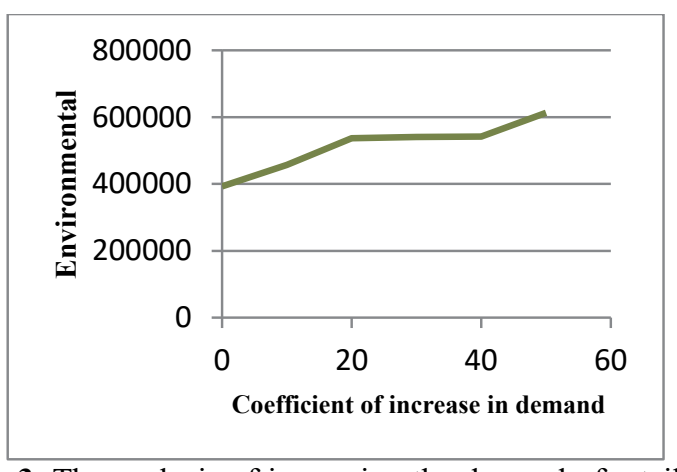

Fig. 3. The analysis of increasing the demand of retailers on environmental objective

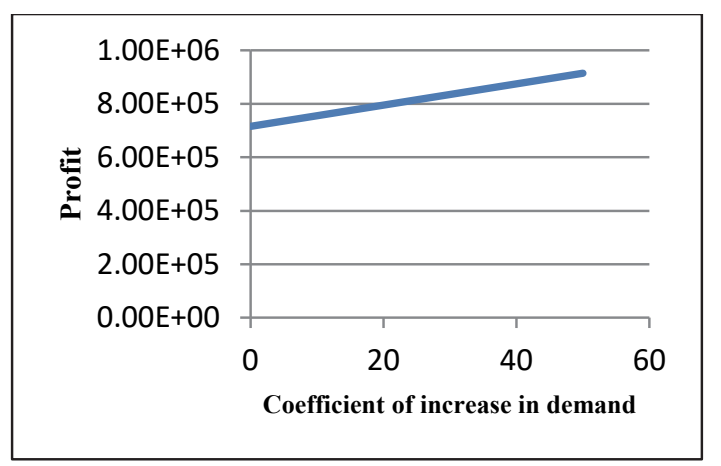

Fig. 2. The analysis of increasing the demand of retailers on profit objective

As shown in Fig. 2, when the retailers' demand increased, sales of the final products increased, which lead to an increase in the overall profit of the chain. Considering a single production center was established, this center sent the final product with direct shipment to retailers that located in Tehran and within its radius. For the other provinces (Alborz, Qazvin and Qom) deliveries were made indirectly through distribution centers. Thus the number of jobs created was proportional to the region's unemployment rate. Therefore, The analysis of increasing the demand of retailers on job created objective would have a constant slope. This increase in demand leads to the use of different transportation capacities, which in turn increases the $\mathrm{CO}_{2}$ emissions from transportation. Thus, as would be expected, the environmental impact diagram is an incremental diagram (Fig. 3). 


\section{Conclusion}

In this research, a mixed integer programming model was proposed for a multi-level sustainable food supply chain network design with regard to capacity constraints for facilities. In the proposed model, decisions were made to locate and allocate facilities to satisfied demand by considering the perishable product that is the most important decisions determined by the model. In the proposed model, the objective functions, maximizing chain profit, considered several parameters as follows: (1) the income from the sale of final products from both direct and indirect transmission methods; (2) the costs of the establishing the production and distribution centers; (3)the cost of purchasing raw materials from suppliers; (4) the cost of transportation throughout the chain; (5) the cost of holding final products in distribution centers regarding to their perishability and (6) the cost of wastewater filtration in the plant; maximizing the number of jobs created in the areas where production and distribution centers were opened; and finally minimizing environmental impacts, including minimizing $\mathrm{CO}_{2}$ emission for the establishment of facilities and transportation in total chain. In addition, this model was also implemented based on data from a case study for kielbasa and sausages processed products in Tehran province by using GAMS software. In order to validate the proposed model, sensitivity analysis was performed on the most important parameter of the problem, namely, the amount of demand, and the results of such computation were reported. As a result, the whole chain profit was increased, but the number of jobs opportunities were fixed and environmental impacts was increased due to changing transportation capacity. Ranges for further research are: (a) further studying the issue of perishability for raw materials; (c) considering uncertainty for possible parameters; and (d) Developing heuristic algorithms to solve large-scale prototypes.

\section{Acknowledgement}

The authors would like to thank the anonymous referees for constructive comments on earlier version of this paper.

\section{References}

Accorsi, R. (2019). Planning Sustainable Food Supply Chains to Meet Growing Demands.

Amorim, P., Curcio, E., Almada-Lobo, B., Barbosa-Povoa, A. P., \& Grossmann, I. E. (2016). Supplier Selection for Supply Chains in the Processed Food Industry. European Journal of Operational Research, 252, 801814.

Amorim, P., Günther, H. O., \& Almada-Lobo, B. (2012). Multi-objective integrated production and distribution planning of perishable products. International Journal of Production Economics, 138(1), 89-101.

Apaiah, R. K., Hendrix, E. M., Meerdink, G., \& Linnemann, A. R. (2005). Qualitative methodology for efficient food chain design. Trends in Food Science \& Technology, 16(5), 204-214.

Atthirawong, W., \& Choomrit, N., (2006). Food supply chain design case of white shrimp industry in Thailand. Proceedings of the 11th Annual Conference of Asia Pacific Decision Sciences Institute Hong Kong, 823-826.

Barzinpour, F., \& Taki, P. (2018). A dual-channel network design model in a green supply chain considering pricing and transportation mode choice. Journal of Intelligent Manufacturing, 29(7), 1465-1483.

Chaabane, A., \& Geramianfar, R. (2015, May). Sustainable supply chain planning and optimization trade-offs between cost, GHG emissions and service level. In 2015 4th International Conference on Advanced Logistics and Transport (ICALT) (pp. 327-332). IEEE.

Goodarzi, A. H., \& Zegordi, S. H. (2016). A location-routing problem for cross-docking networks: A biogeography-based optimization algorithm. Computers \& Industrial Engineering, 102, 132-146.

Grunow, M., \& Piramuthu, S. (2013). RFID in highly perishable food supply chains-Remaining shelf life to supplant expiry date?. International Journal of Production Economics, 146(2), 717-727.

Hiassat, A., \& Diabat, A. (2011, December). A location inventory routing problem with perishable products. In Proceedings of the 41st international conference on computers and industrial engineering (pp. 130-135). Curran Associates, Inc. Los Angeles.

Hiassat, A., Diabat, A., \& Rahwan, I. (2017). A genetic algorithm approach for location-inventory-routing problem with perishable products. Journal of Manufacturing Systems, 42, 93-103.

Jonkman, J., Bloemhof, J. M., Van der Vorst, J. G., \& van der Padt, A. (2017). Selecting food process designs from a supply chain perspective. Journal of Food Engineering, 195, 52-60. 
Kalantari, M., \& Pishvaee, M.S. (2016). A robust possibilistic programming approach to drug supply chain master planning. Journal of Industrial Engineering Research in Production Systems, 4(7), 49-67.

Klincewicz, J. G. (1990). Solving a freight transport problem using facility location techniques. Operations Research, 38(1), 99-109.

Kouki, C., Sahin, E., Jemai, Z., \& Dallery, Y. (2009). Consideration of the Undershoot in an (r, Q) Inventory Model for Perishables. IFAC Proceedings Volumes, 42(4), 1573-1578.

Mavrotas, G., \& Florios, K. (2013). An improved version of the augmented $\varepsilon$-constraint method (AUGMECON2) for finding the exact pareto set in multi-objective integer programming problems. Applied Mathematics and Computation, 219(18), 9652-9669.

Min, H., \& Ko, H. J. (2008). The dynamic design of a reverse logistics network from the perspective of thirdparty logistics service providers. International Journal of Production Economics, 113(1), 176-192.

Min, H., Ko, H. J., \& Ko, C. S. (2006). A genetic algorithm approach to developing the multi-echelon reverse logistics network for product returns. Omega, 34(1), 56-69.

Min, H., Ko, C. S., \& Ko, H. J. (2006). The spatial and temporal consolidation of returned products in a closedloop supply chain network. Computers \& Industrial Engineering, 51(2), 309-320.

Mogale, D. G., Kumar, S. K., \& Tiwari, M. K. (2016). Two stage Indian food grain supply chain network transportation-allocation model. IFAC-PapersOnLine, 49(12), 1767-1772.

Mohammed, A., \& Wang, Q. (2017). The fuzzy multi-objective distribution planner for a green meat supply chain. International Journal of Production Economics, 184, 47-58.

Mohebalizadehgashti, F., Zolfagharinia, H., \& Amin, S. H. (2020). Designing a green meat supply chain network: A multi-objective approach. International Journal of Production Economics, 219, 312-327.

Nakhai Kamalabadi, A., Ghasimi, S.A., \& Ghodsi, R. (2009). Development and improving supply chain inventory control model for perishable items using just-in-time logistic. Journal of Industrial Management Faculty Humanities, 4(9).

Onggo, B. S., Panadero, J., Corlu, C. G., \& Juan, A. A. (2019). Agri-food supply chains with stochastic demands: A multi-period inventory routing problem with perishable products. Simulation Modelling Practice and Theory, 97, 101970.

Pishvaee, M. S., \& Rabbani, M. (2011). A graph theoretic-based heuristic algorithm for responsive supply chain network design with direct and indirect shipment. Advances in Engineering Software, 42(3), 57-63.

Rahimi, M., \& Ghezavati, V. (2018). Sustainable multi-period reverse logistics network design and planning under uncertainty utilizing conditional value at risk $(\mathrm{CVaR})$ for recycling construction and demolition waste. Journal of Cleaner Production, 172, 1567-1581.

Rianthong, N., \& Dumrongsiri, A. (2013). Time-partitioning heuristic algorithm for optimal production, inventory, and transportation planning with direct shipment. Songklanakarin Journal of Science \& Technology, 35(3).

Rohmer, S. U. K., Gerdessen, J. C., \& Claassen, G. D. H. (2019). Sustainable supply chain design in the food system with dietary considerations: A multi-objective analysis. European Journal of Operational Research, 273(3), 1149-1164.

Rong, A., Akkerman, R., \& Grunow, M. (2011). An optimization approach for managing fresh food quality throughout the supply chain. International Journal of Production Economics, 131(1), 421-429.

Jifroudi, S., Teimoury, E., \& Barzinpour, F. (2020). Designing and planning a rice supply chain: a case study for Iran farmlands. Decision Science Letters, 9(2), 163-180.

Varsei, M., \& Polyakovskiy, S. (2017). Sustainable supply chain network design: A case of the wine industry in Australia. Omega, 66, 236-247.

Yakovleva, N., Sarkis, J., \& Sloan, T. W. (2010). Sustainability indicators for the food supply chain. In Environmental Assessment and Management in the Food Industry (pp. 297-329). Woodhead Publishing.

Yu, M., \& Nagurney, A. (2013). Competitive food supply chain networks with application to fresh produce. European Journal of Operational Research, 224(2), 273-282.

Zhang, Q., Luo, J., \& Duan, Y. (2016). Buyer-vendor coordination for fixed lifetime product with quantity discount under finite production rate. International Journal of Systems Science, 47(4), 821-834.

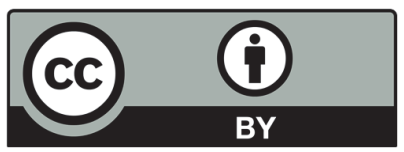

(C) 2020 by the authors; licensee Growing Science, Canada. This is an open access article distributed under the terms and conditions of the Creative Commons Attribution (CC-BY) license (http://creativecommons.org/licenses/by/4.0/). 